Изотехнологии в работе учителя-логопеда DOI 10.20323/978-5-00089-474-3-2021-142-147

Аннотация. Этап автоматизации поставленных звуков, особенно у детей с тяжелыми нарушениями речи, - длительный и сложный процесс. Чтобы сделать этот процесс более интересным и занимательным для ребенка, мы активно применяем в своей работе изобразительные технологии. Изготавливая пластилиновые картинки, учитель-логопед может эффективно взаимодействовать с детьми, которым оказывается логопедическая помощь.

Ключевые слова: изобразительные технологии, автоматизация поставленных звуков, пластилиновые картинки, учитель-логопед, логопедическая помощь.

K.V. Nagle

\title{
Izotechnologies in the work of the teacher-speech therapist
}

Abstract. The stage of automating the set sounds, especially in children with severe speech disorders, is a long and complex process. To make this process more interesting and entertaining for the child, we actively use visual technologies in our work. By making plasticine pictures, a speech therapist teacher can effectively interact with children who receive speech therapy assistance.

Keywords: visual technologies, automation of sounds, plasticine pictures, speech therapist teacher, speech therapy assistance.

Одно из направлений коррекционной работы учителя-логопеда дошкольного образовательного учреждения - автоматизация поставленных звуков в речи. С физиологической точки зрения этап автоматизации звука представляетсобой закреплениеусловно-рефлекторных речедвигательных связей наразличном речевом материале. Поставленный звук ещё очень хрупкий, условно-рефлекторная связь без подкрепления может быстро разрушиться.

Автоматизировать звук - это значит ввести его в речь на всех уровнях: в слоги, в слова, в предложения и в связную речь [Филичева, Туманова, 2000]. Этап автоматизации поставленных звуков, особенно у детей с тяжелыми нарушениями речи (далее - ТНР) - длительный и

(C) Нагле К.В., 2021 
сложный процесс. Чтобы сделать этот процесс более интересным и занимательным для ребенка, сформировать у воспитанников прочную связь слова с предметом, который оно обозначает, в своей коррекционной работе мы применяем изобразительные технологии.

О широком развивающем значении изобразительной деятельности писали художники, педагоги, психологи: А. В. Запорожец, Е. И. Игнатьев, В. С. Кузин, Б. М. Неменский, Н. Н. Ростовцев, Н. П. Сакулина, Б. М. Теплов, Е. А. Флерина, П. П. Чистяков, Т. Я. Шпикалова, Б. П. Юсов и др. Большую познавательную роль рисования отмечал К.Д. Ушинский. Рисование, по мнению К.Д. Ушинского, является одним из лучших средств развития наблюдательности, а вместе с тем памяти, мышления и воображения [Алябьева, 2009; Мастюкова, 1997]. Ребенок создает изображение не только на основе того, что он непосредственно воспринимает. Образ только что воспринятого предмета у него вступает во взаимосвязь с опытом прошлых восприятий и сложившихся образных представлений.

Значение изобразительной деятельности в воспитании и развитии различных сторон личности ребенка отмечают и зарубежные ученые: Б. Джефферсон, Э. Крамер, В. Лоунфельд, У. Ламберт, К. Роуланд и др. Так, К. Роулад утверждает, что изобразительная деятельность способствует культурному развитию личности. Э. Крамер подчеркивает значение этой деятельности для интеллектуального развития и формирования зрелой личности. Интеллектуальной деятельностью называет изобразительное творчество и американский ученый В. Лоунфельд, указывая на его важную роль в эмоциональном развитии ребенка. Великий чешский педагог Я.А. Коменский, утверждая важность рисования для формирования всестороннего развития человека, предлагал внести этот предмет в материнские школы как необходимое занятие для развития наблюдательности, ощущений ребенка.

О важном значении рисования для всестороннего воспитания и образования ребенка писал известный немецкий педагог Ф. Фребель, создатель учреждения для воспитания детей дошкольного возраста детского сада, разработавший уникальную по тем временам систему воспитания малышей, в которой большое место отводилось ручным занятиям, включающим рисование и лепку [Мастюкова, 1997].

Одним из значимых средств всестороннего развития детей, в том числе и речи, является такой вид изобразительной деятельности, 
как пластилинография, которая включает в себя и рисование, и лепку, и аппликацию [Тарасова, 2011].

Рисование тесно связано с развитием наглядно-действенного и наглядно-образного мышления, а также с выработкой навыков анализа, синтеза, сопоставления, сравнения, обобщения. Работая над рисунком, дошкольники учатся выделять особенности, качества, внешние свойства предметов, главные и второстепенные детали, правильно устанавливать и соотносить одну часть предмета с другой, передавать пропорции, сравнивать величину деталей, сопоставлять свой рисунок с натурой, с работами сверстников. Создание образа невозможно без обобщения, без целостного восприятия предметов. На основе умственных операций ребенок представляет результат своей работы, учится оперировать понятиями.

Таким образом, использование нетрадиционных техник изображения, в частности - пластилинографии, способствует развитию познавательной деятельности, коррекции психических процессов и личностной сферы, а также развитию речи дошкольников с ОНР IIIIV уровня в целом.

Как показывает практика, чтобы достичь лучших результатов, к этапу автоматизации поставленных звуков в речи должны подключаться и воспитатели ДОУ. Посредством пластилиновых картинок, изготовленных детьми самостоятельно, учитель-логопед может эффективно взаимодействовать с воспитателями детей, которым оказывается логопедическая помощь. Уже более 10 лет мы осуществляем взаимодействие с воспитателями по такому направлению, как автоматизация звуков в речи с помощью «пластилиновых картинок». Картинки изготавливаются детьми самостоятельно в свободное время.

Как известно, дети с нарушениями речи, особенно дети с общим недоразвитием речи, отличаются недостаточной сформированностью мелкой моторики, плохой координацией движений, недостаточностью самоконтроля и пространственно-временной ориентировки. Необходимость развития моторики рук, обусловлена тесным взаимодействием ручной и речевой моторики. Совершенствование мелкой моторики способствует активизации моторных речевых зон головного мозга.

По нашему мнению, именно изобразительная деятельность с применением различных нетрадиционных художественных техник, в том числе и пластилинографии, развивает мелкую моторику пальцев 
рук, творческие способности детей любого возраста, способствует эстетическому и нравственному развитию, расширению кругозора, развитию сенсорного восприятия, глазомера, воображения и речи.

Пластилинография -это один из видов декоративно-прикладного искусства, представляющий собой создание на картонной основе с помощью пластилина лепных картин с изображением выпуклых, полуобъемных объектов на горизонтальной поверхности. Техника проста в исполнении, не требует особых способностей, увлекает и не перегружает детей ни умственно, ни физически.

Материал для создания пластилиновой картинки: картон (размер $10 \times 15$ см.) с контурным рисунком: его делает логопед после индивидуального занятия, на обратной стороне картона пишется имя и фамилия ребенка, название предмета, который должен он изобразить ребенок;набор пластилина, доска, стека, альбом для фотографий $10 \times 15$ см.Изготовленные картинки ребенок помещает в специальный индивидуальный альбом для фотографий, размер вкладышей - $10 \times 15 \mathrm{~cm}$.

Способы изображения предметов могут быть различными: рисование пластилином, пластилинография, пластилиновая аппликация.

Этапы создания «пластилиновых картинок» таковы:

1. Логопед рисует контур предмета на картоне.На обратной стороне картона логопед пишет имя и фамилию ребенка, название предмета, упражнение для закрепления звука в речи - это информация для воспитателя.

2. Логопед обсуждает ребенком способ изображения предмета и его цвет.

3. Ребенок в свободное вечернее время раскрашивает картинку пластилином.

Ребенок самостоятельно подготавливает свое рабочее место (берет картинку, клеенку, пластилин). Прежде чем приступить к раскрашиванию, ребенок разогревает пластилин в своих кулачках, отламывает небольшое количество пластилина и сжимает его в кулачках, перекладывая кусочек пластилина из одного кулачка в другой. Таким образом, осуществляется разминка кисти. Затем ребенок скатывает в ладонях кусочек пластилина, образуя шарик. Шарик раскатывается и получается жгутик. Таким образом, осуществляется массаж ладошек. Ребенок отламывает от жгутика большим и указательным пальцами небольшой кусочек пластилина и прикладывает его на контур, по которому затем размазывает пластилин. Таким образом, осуществляется рисование пластилином. Можно использовать и пластилиновую аппликацию. 
Затем ребенок подходит к воспитателю, который проводит с ним логопедические игры или упражнения на автоматизацию отрабатываемого звука с использованием сделанной ребенком картинки. После этого ребенок убирает свое рабочее место, помещает картинку в свой индивидуальный альбом. Желательно альбомы хранить в группе в речевом уголке, чтобы дети имели свободный доступ к ним и в свободное время могли самостоятельно заниматься автоматизацией поставленных звуков.

Целесообразно создавать коллекции «пластилиновых картинок» по лексическим темам и проводить различные дидактические игры и упражнения на формирование грамматического строя речи, развитие психических процессов: восприятия, памяти, образного и вербального компонентов воображения.

Оригинальность нашей методики заключается в том, что дети самостоятельно изготавливают наглядный материал для проведения логопедических игр и упражнений, активно развивая при этом мелкую моторику рук, образный компонент воображения и речь; у детей создается коллекция пластилиновых картинок с изображенными на них различными предметами, в названии которых «живет» поставленный и автоматизируемый в речи звук; альбом с пластилиновыми картинками может стать и своеобразным «логопедическим портфолио»; пластилиновые картинки, изготовленные детьми, универсальны, так как с их помощью педагоги могут проводить коррекционную работу по автоматизации поставленных звуков на всех уровнях: изолированно, в слогах, в словах, в словосочетаниях, в предложениях, в чистоговорках и в связной речи; воспитатели имеют актуальные знания об этапах коррекционной работы по автоматизации звуков; с помощью пластилиновых картинок педагоги могут развивать и совершенствовать все стороны речи: грамматическую, и фонетическую и связную речь.

\section{Библиографический список}

1. Азова Е.А. Учим звуки. Домашняя логопедическая тетрадь / Е.А. Азова, О.О. Чернова. Москва : ТЦ «Сфера», 2010.24 с.

2. Акименко В.М. Развивающие технологии в логопедии. Ростов-на-Дону : Феникс, 2011. 109 с.

3. Алябьева Е.А. Игры для детей 4-7 лет: развитие речи и воображения. Москва : ТЦ «Сфера», 2009. 128 с.

4. Давыдова Г.Н. Нетрадиционные техники рисования в детском саду. Часть 2. Москва : Скрипторий 2003, 2007. 71 с. 
5. Мастюкова Е.М. О расстройствах памяти у детей с недоразвитием речи // Дефектология. 1972. № 5. С. 12-17.

6. Тарасова Н.В. Обучение дошкольников технике рисования пластилином // Справочник старшего воспитателя дошкольного учреждения. 2011. № 11. С. 52-55.

7. Филичева Т.Б. Дети с общим недоразвитием речи. Воспитание и обучение / Т.Б. Филичева, Т.В. Туманова. Москва :«Издательство Гном и Д», 2000. 128 с.

УДК 376.4

М.Р. Савченко

\section{Особенности представлений о неживой природе школьников с умственной отсталостью}

DOI 10.20323/978-5-00089-474-3-2021-147-153

Аннотаџия. В статье обсуждается состояние представлений о космосе как одном из элементов представлений о неживой природе детей с умственной отсталостью, обучающихся в 3-6 классах. Обращается внимание на наличие связи между состоянием представлений школьников и характером изучения данных понятий, на наличие возрастной динамики представлений о неживой природе у школьников с умственной отсталостью в период их обучения с 3 по 6 класс.

Ключевые слова:школьники с умственной отсталостью, представления о неживой природе.

\section{M.R. Savchenko}

\section{Features of ideas about the inanimate nature of schoolchildren with} mental retardation

Abstract. The article discusses the state of ideas about the cosmos as one of the elements of ideas about the inanimate nature of children with mental retardation studying in grades 3-6. Attention is drawn to the relationship between the state of students ' ideas and the nature of the study of these concepts, to the presence of age-related dynamics of ideas about inanimate nature in students with mental retardation during their education from 3rd to 6 th grade.

Keywords: schoolchildren with mental retardation, ideas about inanimate nature.

(C) Савченко М.P., 2021 